Bulletin d'Histoire Contemporaine de l'Espagne

$54 \mid 2020$

Les espaces du politique dans l'Espagne du Trienio liberal (1820-1823)

\title{
EXPLICATION DE L'ESPAGNE, UN LIBRO DE ELENA RIVERA DE LA SOUCHÈRE DESGLOSADO EN «RADIO PARÍS», 1962
}

Explication de l'Espagne, un livre d'Elena Rivera de la Souchère déchiffré sur les ondes de «Radio París», 1962

Explication de l'Espagne, a book by Elena Rivera de la Souchère decrypted on «Radio París», 1962

Francisco ROJAS CLAROS, María LOSADA URIGÜEN y Gaizka FERNÁNDEZ SOLDEVILLA

\section{OpenEdition} Journals

Edición electrónica

URL: http://journals.openedition.org/bhce/3383

DOI: 10.4000/bhce.3383

ISSN: 1968-3723

Editor

Presses Universitaires de Provence

Edición impresa

Fecha de publicación: 1 enero 2020

ISSN: 0987-4135

Referencia electrónica

Francisco ROJAS CLAROS, María LOSADA URIGÜEN y Gaizka FERNÁNDEZ SOLDEVILLA, «EXPLICATION DE L'ESPAGNE, UN LIBRO DE ELENA RIVERA DE LA SOUCHËRE DESGLOSADO EN «RADIO PARÍS», 1962 », Bulletin d'Histoire Contemporaine de l'Espagne [En línea], 54 | 2020, Publicado el 01 julio 2020, consultado el 03 enero 2021. URL : http://journals.openedition.org/bhce/3383 ; DOI : https://doi.org/10.4000/bhce.3383

Este documento fue generado automáticamente el 3 enero 2021.

Bulletin d'histoire contemporaine de l'Espagne 


\section{EXPLICATION DE L'ESPAGNE, UN LIBRO DE ELENA RIVERA DE LA SOUCHÈRE DESGLOSADO EN «RADIO PARÍS», $1962^{1}$}

Explication de l'Espagne, un livre d'Elena Rivera de la Souchère déchiffré sur les ondes de «Radio París», 1962

Explication de l'Espagne, a book by Elena Rivera de la Souchère decrypted on «Radio París», 1962

Francisco ROJAS CLAROS, María LOSADA URIGÜEN y Gaizka FERNÁNDEZ SOLDEVILLA

\section{Introducción}
«Ningún español joven conoce hoy su nombre [...] incluso en estos días de la tan traída y llevada recuperación de la memoria histórica, una personalidad tan singular como la de Elena de la Souchère, que tanto hizo por la causa republicana y por la libertad de nuestro país, permanece en un vergonzoso olvido. Es hora de que todos aquellos por quienes desinteresadamente luchó reconozcamos el valor de su ejemplo y de su fértil
y asendereada vida» ${ }^{2}$.

«Radio París» era el nombre popular con el que eran conocidas las Emisiones en Lenguas Ibéricas de la Radiodifusión-Televisión Francesa, una de las emisoras más importantes de las que funcionaban en el exterior de España durante los años del franquismo. En esencia, se trataba de una emisora estatal francesa dirigida por 
hispanistas e integrada mayoritariamente por exiliados republicanos, lo que le confería un fuerte componente antifranquista. Formaba parte del monopolio de la RTF, denominado más tarde ORTF (Oficina de la Radiodifusión-Televisión Francesa), cesando sus emisiones a partir de agosto de 1974. En este trabajo se ofrece la transcripción de las ocho grabaciones conservadas entre sus fondos del programa radiofónico «Explicación de España, un libro de Elena de la Souchère», que fue emitido a lo largo de 1962. Se trataba de una mesa redonda constituida por la autora del texto y tres importantes personalidades de la emisora: los hispanistas franceses André Camp (director de las emisiones en aquel momento) y Jean Supervielle, y el locutor donostiarra exiliado Julián Antonio Ramírez.

2 André Camp fue director de la emisora durante el período 1958-1968. Durante ese tiempo la reubicó definitivamente en París desde Toulouse (su sede desde el fin de la II Guerra Mundial), recuperó las emisiones destinadas a América Latina, reintrodujo corresponsales en el interior de España y creó las emisiones en vasco, gallego y catalán. Profesor de Geografía e Historia, locutor y periodista, crítico y adaptador teatral y antiguo miembro de la Resistencia durante la ocupación alemana, Camp se definía a sí mismo como "historien de formation et hispanisant par vocation", siendo hijo de otro importante hispanista, el profesor Jean Camp (organizador, entre otras cosas, de las célebres Décadas Literarias de Provenza, de carácter anual) ${ }^{3}$. Jean Supervielle era el adjunto de André Camp por aquel entonces y le acabó sucediendo en la dirección, cargo que ocuparía entre 1969 y diciembre de 1975, un período difícil y de constantes recortes que acabaría con el desmantelamiento de «Radio París» como tal. Era hijo del hispanista franco-uruguayo Jules Supervielle, gran amigo de los escritores de la Generación del $27^{4}$. Mientras que el locutor y redactor donostiarra Julián Antonio Ramírez Hernando fue un luchador republicano incansable, militante del PCE y vasquista comprometido, actor de teatro y de doblaje cinematográfico que llegaría a ser jefe de redacción en la emisora a partir de 1968. Estuvo casado con la locutora catalana igualmente célebre Adela Carreras Taurà, más conocida como Adelita del Campo. Actriz, bailarina, anarquista, activista feminista y militante comunista. Tras el fin de la Guerra Civil estuvo recluida -al igual que Ramírez- en distintos campos de concentración para refugiados en Francia, de ahí su sobrenombre. De hecho, se conocieron en el campo de Argelès-sur-Mer (cerca de Perpiñán). Ambos participaron activamente en la Resistencia durante la ocupación de Francia y no retornaron definitivamente del exilio hasta la muerte de Franco ${ }^{5}$.

3 En cuanto a la propia Elena Rivera de la Souchère, hispanista catalano-francesa, mantuvo importantes vinculaciones a lo largo de su vida con el nacionalismo vasco, hasta el punto de recibir en 1989 el «Premio Sabino Arana», en reconocimiento a sus más de 50 años de apoyo al mismo. Fue hija del arqueólogo Romualdo Rivera de la Souchère, amigo personal de Manuel Irujo y fundador del primer Museo Picasso (Antibes). Era colaboradora de la delegación del Gobierno vasco en París durante la Guerra Civil. Corresponsal de guerra a sus 18 años en Madrid y luego en Barcelona, donde defendió a los sacerdotes vascos refugiados allí, amenazados por grupos extremistas incontrolados del bando republicano durante los primeros meses de la contienda. Miembro de la Liga Internacional de Amigos de los Vascos, colaboró en publicaciones como Gudari (1937) y fue una importante activista por la causa republicana en Europa. Refugiada en Londres tras la ocupación alemana de Francia, negoció junto a Manuel de Irujo la creación de las Brigadas Vascas y con De Gaulle la 
ayuda a los resistentes y la formación de una Brigada Vasca en Francia. Prestó soporte a los republicanos liberados de los campos de concentración del Gobierno de Vichy. Y durante los largos años del franquismo significó un nexo importante entre amplios sectores del exilio y de la disidencia interior a la dictadura, cuya causa defendió en diversos medios internacionales a los que tuvo acceso (a lo largo de las transcripciones se cita buena parte de los mismos). Fue muy amiga de dirigentes históricos exiliados del PNV y de importantes figuras de la historiografía, como Manuel Tunón de Lara en su etapa de París ${ }^{6}$, y tuvo muy buena relación con el canónigo Alberto Onaindía, más conocido como el «Padre Olaso», a quien conoció durante la Guerra Civil, tal y como ella misma relató en sus memorias. Amigo personal del Lehendakari José Antonio de Aguirre, testigo del bombardeo de Gernika, activo negociador en el Pacto de Santoña y uno de los supervivientes de los fusilamientos de sacerdotes nacionalistas vascos perpetrados por los sublevados (entre cuyas víctimas estuvo su hermano, el también sacerdote Celestino de Onaindía). Exiliado en Londres y locutor de la BBC se convirtió -entre 1946 y 1957- en uno de los colaboradores más importantes de "Radio París» y más combativos frente a la dictadura, hasta que las presiones del Gobierno franquista lograron su cese en noviembre de $1957^{7}$. Sus intervenciones radiofónicas en esta emisora fueron publicadas en 5 tomos bajo el título Obras completas de Alberto de Onaindia: Charlas del sacerdote doctor Olaso en la Radiodifusión Francesa. Años 1946-1957 (Bilbao, Gran Enciclopedia Vasca, 1980).

4 Explication de l'Espagne (Paris, Bernard Grasset, 1962) fue uno de los textos de Elena Rivera de la Souchère más importantes y con mayor repercusión, aunque nunca se tradujo al castellano. Es más, entre los fondos de censura bibliográfica del Archivo General de la Administración no aparecen indicios de que se hubiera intentado publicar en España, ni siquiera tras la Ley de Prensa e Imprenta de 1966, de corte supuestamente «aperturista». Lo cual confiere a estas transcripciones una importancia histórica añadida ${ }^{8}$. No obstante, el Ministerio de Información y Turismo de la dictadura conocía su existencia. De hecho, el Boletín de Orientación Bibliográfica ${ }^{9}$ le dedicó un despiadado artículo, gracias al cual puede conocerse el parecer de la censura franquista sobre el texto y su autora. Para los censores, «[...] toda la obra está tarada por un vicio de origen: Elena de la Souchère adopta una posición, un punto de vista [subjetivo] para enjuiciar nuestro país» - según ellos- haciendo pasar por objetivas y razonadas sus interpretaciones personales. $\mathrm{Y}$ aunque las dos primeras partes se consideraron interesantes, su supuesta subjetividad se acentuaba en la tercera parte:
«[...] para ella, nada se puede esperar de determinadas instituciones como la Iglesia,
o de determinados tipos humanos: militares, conservadores, burgueses, terratenientes. Tampoco de determinadas ideas, porque simbolizan y encarnan el fanatismo, la intolerancia, el dogmatismo; un pasado, en suma, periclitado. La libertad, el progreso, la evolución, sólo pueden venir del otro lado: el de los librepensadores, de los agnósticos, de los antidogmáticos; de una juventud dispuesta a romper con el pasado. De aquel lado está siempre la injusticia y la opresión. De éste, un mundo más justo, próspero y feliz».

5 Del mismo modo, fue acusada de reducir a Franco a una mera caricatura: «[...] puesto que no puede acusarle de inmoralidad y de corrupción [...] distorsiona algunos rasgos de su carácter -otros los ignora por completo o los falsea con vileza- hasta hacer su pretendido retrato irreconocible». En conclusión, un libro que:

«podría haber sido, en efecto, una explicación interesante, sagaz y profunda de nuestra Patria, se convierte así en una interpretación falsa, tendenciosa y sectaria. 
No se puede dar una prueba mayor de mala fe y de intolerancia que la que Elena de

la Souchère da en su pretendida Explicación de España» ${ }^{10}$.

\section{Presentación del libro, descripción y primeras impresiones}

6 Año: 1962 Duración: 16 min., 29 seg. Signatura: FO RP/0472. Fondo sonoro: Radio París. Ramírez/del Campo

7 http://devuelvemelavoz.ua.es/devuelveme-voz/visor.php? idioma $=$ es\&fichero=9581.mp3

RAMÍREZ: Explicación de España es el título de un libro que acaba de publicar la editorial parisiense Grasset, y que ha despertado un interés excepcional. Varias emisiones de radio se le han dedicado ya, y ésta es una más que creemos también excepcionalmente interesante, pues se trata de analizar un libro que presenta a España de una manera muy lúcida, como pocas veces se ha presentado. La autora del libro es Elena de la Souchère, conocida periodista, colaboradora regular de revistas como France Observateur y Les Temps Modernes - la revista de Jean Paul Sartre-. También colaboró en Esprit y en otras publicaciones francesas y de otros países. Al presentar Explicación de España a nuestros oyentes tenemos que empezar diciendo que el título despertó en nosotros - por lo menos en mí- cierta inquietud. Explicar... explicar España. Ahí es nada, como se dice en España. Ahí es nada. Explicar el país del paraíso de la paradoja. Me pareció ambicioso el título pero, después de la lectura, he de reconocer que corresponde a la verdad. Tal vez no sea «la explicación» de España... la explicación completa, total, pero es una -a mi juicio- explicación de España muy válida. Y de ahí el interés que para nosotros ofrece este título.

CAMP: Pero antes yo creo que hay que añadir que Explicación de España, título del libro de Elena de la Souchère que tenemos esta noche con nosotros en nuestros micrófonos, es un libro escrito en francés y el título original es Explication de l'Espagne. Eso también necesita una pequeña explicación porque, desde hace unos meses, en las editoriales francesas, España ha suscitado varios libros. Libros sobre la historia de los últimos años, o de la Guerra de España, de los cuales ya hemos hablado. Pero éste, el de Elena de la Souchère, Explication de l'Espagne de la editorial Grasset, es una especie de síntesis y vamos a pedir a Elena de la Souchère que ella misma nos explique lo que quiso hacer.

RAMÍREZ: Y para ello estamos reunidos ante estos micrófonos la autora, Elena de la Souchère, André Camp, director de las emisiones en español de la RadiodifusiónTelevisión Francesa, Jean Supervielle y un servidor.

SOUCHÈRE: Bueno, lo primero, hay que aclarar el título. Este libro, esta Explicación de España, merece una explicación. En realidad el título no es mío. El título, que me parece ambicioso, tan ambicioso y presumido como absurdo en un sentido... ¿Quién puede explicar España? Pues este título me ha sido impuesto por la editorial, por el editor, quien quiere publicar, con este mismo título, una serie de ensayos políticos dedicados a distintos países: Explicación de Alemania, Explicación de Italia, Explicación de China,... y qué sé yo.

CAMP: Es el primero entonces de esa colección sobre explicaciones de diferentes países. $\mathrm{Y}$ yo creo que es interesante que esa colección lanzada por una editorial francesa empiece por una explicación de España. 
RAMÍREZ: Yo creo que si logran explicar España, será muchísimo más fácil hacerlo con los otros países.

SOUCHÈRE: Sí, seguro.

RAMÍREZ: Bueno, yo me voy a permitir hacerle una pregunta indiscreta. Ya que no es de usted el título ¿cuál hubiera sido el título que usted hubiese dado a su libro?

SOUCHÈRE: Había presentado como diez títulos... ninguno bueno, en realidad. Ninguno que enfocase la totalidad del libro, pues uno respondía a la parte -digamos- histórica; otro, a la última parte, que es un análisis de la situación de la coyuntura... Todos han sido rechazados porque además, como acabo de explicar, la editorial tenía su propio criterio, ya quería inaugurar su nueva colección de ensayos políticos con ese mismo título, con un ensayo sobre España.

SUPERVIELLE: ¿Usted escribió el libro directamente en francés?

SOUCHÈRE: He tomado los apuntes en castellano porque la mayor parte de la documentación es española. Puedo decir que exclusivamente española. De libros publicados en España y en el mundo hispanoamericano. De modo que los apuntes los tomé en castellano, en español.

CAMP: Sí, pero su idioma de trabajo, como periodista, como escritora, es el francés... SUPERVIELLE: Parece usted española también...

SOUCHÈRE: Escribo también en castellano. Para la prensa latinoamericana, para el Excelsior de México.

SUPERVIELLE: Es bilingüe.

RAMÍREZ: Es un libro muy voluminoso, 350 páginas de letra bastante apretada.

SUPERVIELLE: Y creo incluso que ha sido reducido ¿no? La editorial se lo pidió porque al principio era mucho más largo ¿no?

SOUCHÈRE: He cortado aproximadamente la mitad.

RAMÍREZ: Bueno, yo iba a preguntarle... es el fruto de un gran trabajo, es lo primero que se ve. La primera impresión que se deduce de la lectura de este libro es que es el fruto de un trabajo muy profundo.

SOUCHÈRE: La portada ha sido un trabajo fenomenal [ríe].

RAMíREZ: No, y el escribirlo, me refiero al escribirlo también. ¿Cuánto tiempo le ha costado?

SOUCHÈRE: Bueno, un año para tomar los apuntes, un año para escribirlo y tres años para cortarlo y ponerme a luchar contra las editoriales.

RAMÍREZ: Y luego los meses que ha tardado usted en actualizarlo, porque al final lo pone al día.

SOUCHÈRE: Claro... no, cada vez tenía que actualizarlo, ya lo he actualizado como tres veces.

SUPERVIELLE: ¿Y cómo se ha documentado usted? Porque creo que usted no ha regresado a España desde hace varios años ¿No es así?

SOUCHÈRE: Sí, desde el año 39. Llevo fuera 23 años.

RAMÍREZ: Eso nos lleva, eso nos lleva a hacer algunas preguntas acerca de su nacionalidad, porque Elena de la Souchère es un apellido -un cognom, como se dice en francés- muy francés. Pero Elena -que es el nombre de pila con que usted firma siempre- es muy español. Podría creerse que adoptaba el nombre de pila de Elena para marcar su hispanismo, pero no. Es algo más ¿verdad?

SOUCHÈRE: No, no, es mi nombre de pila auténtico. Yo me llamo Elena de Rivera, y la Souchère es el apellido de mi madre.

RAMÍREZ: ¿Y usted es española? 
SOUCHÈRE: Yo soy española. Nacida en Barcelona.

RAMÍREZ: Formada en Francia, sin duda.

SOUCHÈRE: Formada en Francia. Aparte, he llegado muy joven.

RAMÍREZ: Y mira usted las cosas de España con pasión española o con ¿cómo diré yo? ¿Con alteza francesa?

SOUCHÈRE: Ustedes dirán pasión sí, con corazón español, indiscutiblemente. Pero si tengo una formación francesa, si se me nota la formación francesa, yo no sé hasta qué punto... Desde luego yo veo el problema de España desde dentro, no viviendo en España, en la tierra de España, pero sí desde mi corazón español en este sentido, desde dentro y desde fuera, viviendo en Francia, con una formación francesa y con información francesa.

RAMÍREZ: Yo creo que la combinación es excelente. Y no sé si me equivocaré, pero la impresión primera que se deduce del libro es que domina... afortunadamente, digo afortunadamente... domina la serenidad, la objetividad del observador de fuera, porque otra de las lecciones que se saca, que un español saca de la lectura de este libro es una lección de humildad, es la de que no puede comprenderse bien España ni explicarse bien España sino desde fuera.

SOUCHÈRE: Pues yo no sé, yo creo que principalmente porque en España escasea la documentación...

RAMÍREZ: Será por eso...

SOUCHÈRE: Será por eso.

SUPERVIELLE: $Y$ entonces usted cómo llegó a documentarse ¿a través de periódicos, a través de contactos?

SOUCHÈRE: A través de... Bueno, les voy a decir algo que al parecer contradice lo que dije... lo que dije sobre la escasez de documentación. Porque la mayor parte de la documentación de tipo estadístico... la he traído de España. Ustedes saben que, al fin y al cabo, España es uno de los países que tiene... donde se desarrolla una labor estadística maravillosa. Con algunas limitaciones y dificultades, pero por lo menos hay abundancia.

RAMÍREZ: ¿De datos estadísticos?

SOUCHÈRE: De datos estadísticos.

RAMÍREZ: Fidedignos, sinceros...

SOUCHÈRE: Pues como no tenemos otros...

RAMÍREZ: Otros criterios...

SOUCHÈRE: Otros criterios, otros datos estadísticos sobre España, porque ni en los países extranjeros ni en la emigración política tenemos [ni] se ha realizado una labor estadística fidedigna, y como desde dentro no tenemos sino fuentes oficiales, he creído que lo mejor era atenerme, tener en cuenta los datos estadísticos de fuente oficial. Con todas las incógnitas, todos los interrogantes y todas las limitaciones que pueden plantearse.

RAMÍREZ: Pues en el libro se ve que ha tenido usted una fuente abundantísima en efecto, porque es un libro muy documentado. Es una de sus características, sí.

CAMP: Y además como dice su título, Explicación de España no se trata de un ensayo o un estudio político de la situación actual de España, sino también una síntesis, empezando por el principio. Y la primera parte de su libro se llama «Presencia del pasado». Usted dijo hace un momento que tuvo que cortar la mitad de su libro, la mitad de su manuscrito... Entonces ¿qué quitó de lo que queda?

RAMÍREZ: ¿Quitó del pasado o del presente? 
SOUCHÈRE: Bueno, en realidad he quitado sobre todo del pasado. Pero hubiera querido hacer una pequeña aclaración sobre... no hemos agotado el tema de la documentación. RAMÍREZ: De la documentación...

SOUCHÈRE: Porque lo que dije, al parecer implicaba una contradicción fundamental, porque empecé diciéndoles que en España hay escasez de documentación y acabé diciendo que toda la documentación la saqué de España. Y que quise enfocar los problemas económicos de España a través de una documentación de tipo oficial. Esto, en lo económico. Pero en lo político... pues he utilizado las informaciones periodísticas, las informaciones de las agencias... es decir, una serie de noticias que en la mayor parte del tiempo no se publican por varios motivos en la prensa española. De modo que he tenido al mismo tiempo una documentación de dentro y una documentación de fuera. Aclarando las informaciones de tipo político, los telegramas publicados en la prensa internacional, por la información estadística de dentro [sic] e interpretando la información estadística, la información oficial, a través de los despachos de la prensa internacional.

CAMP: Sí, pero la prensa internacional de todas maneras manda su despacho de dentro de España... Se utilizan fuera, pero la fuente es en España misma...

RAMÍREZ: En cuanto a los datos económicos creo que no hay problema. Creo que los datos oficiales son una fuente válida de documentación. Ahora, en cuanto a la documentación política, ahí sí es donde reside el problema de la posible parcialidad... parcialidad, no falta de objetividad, pero parcialidad. Es decir, carácter incompleto de las informaciones que pueden tomarse según a quién se dirija uno.

SOUCHÈRE: Sí, por esto hay que complementar las informaciones de dentro con las informaciones de fuera, y las informaciones difundidas por la prensa izquierdista, por informaciones objetivas, difundidas por ejemplo por la prensa norteamericana, que suele ser muy bien informada, y por la prensa Suiza, prensa de los Países Escandinavos... en fin, prensa que ve los problemas de España desde lejos.

RAMÍREZ: De todos modos ¿no cree usted que ése es uno de los escollos para un trabajo de este género? Ya hablamos de ello, me acuerdo ¿verdad, André Camp? con el autor inglés Hugh Thomas...

CAMP: Sí. Que escribió una historia de la Guerra Civil Española...

RAMÍREZ: A propósito de su libro. Y nos confesó que se veía obligado a rectificar... pues casi continuamente algunas de las afirmaciones que hacía en su libro. Yo, en efecto, encontré algunas inexactitudes de cosas, de hechos que había vivido yo personalmente. Y él confesó muy horadamente que a cada español con quién se encontraba, pues se veía en la obligación de rectificar algunas de las cosas. Eso es lo que me ha hecho pensar a mí en las dificultades con que ha debido de tropezar usted, para documentarse sobre todo en la parte política del libro.

SOUCHÈRE: Sí, y entonces hay una tercera... Para orientarse, hay una tercera fuente de información que son los contactos personales. Que suelen ser abundantes en mi caso, ya que tengo muchas amistades en España. Entre la gente que va y viene...

SUPERVIELLE: Sí, y que le permiten comprobar los datos oficiales y todo eso.

RAMÍREZ: Creo que ahora ya vemos un poco más claro en el caminar que ha llevado a usted a elaborar este libro. Tal vez sería ya el momento de presentar una semblanza, un aspecto general del libro, decir cómo está estructurado. Creo que hay que decir que después de un prólogo, de un capítulo preliminar - se llama- cuyo título es muy sugestivo: en francés es «Un peuple malade de son histoire», «Un pueblo enfermo de su historia», el libro consta de tres grandes partes. La primera parte es la parte histórica y 
se titula «Presencia del pasado». La segunda parte -histórica también pero contemporánea- se llama, se titula «El fracaso de la democracia representativa». Y la tercera parte de este libro, que se refiere a la actualidad, a la coyuntura, a la situación actual, se titula -también de una manera muy sugestiva- «El tiempo inmóvil». Yo no sé si tendríamos tiempo... móvil [ríen] de entrar en el detalle de cada una de estas partes, si a ustedes les parece bien, en sucesivas emisiones...

CAMP: Claro. Además, el tema merece desarrollarse con calma y lo más completamente posible.

RAMÍREZ: Así pues, cuando pasen estas vacaciones de verano -ya lo anunciaremos oportunamente- ofreceremos a nuestros oyentes una serie de emisiones más detalladas acerca de este interesante libro de Elena de la Souchère, Explication de l'Espagne - Explicación de España.

\section{Un pueblo enfermo de su historia. España y las Españas}

8 Año: 1962. Duración: 15 min., 30 seg. Fondo sonoro: Radio París. Ramírez/del Campo. Signatura: FO RP/0490.

9 http://devuelvemelavoz.ua.es/devuelveme-voz/visor.php? idioma=es\&fichero=9601. $\mathrm{mp3}$ [Suena sintonía]

ADELITA DEL CAMPO: Explicación de España, un libro de Elena de la Souchère presentado por André Camp, Jean Supervielle y Julian Antonio Ramírez.

RAMÍREZ: Hace algún tiempo, coincidiendo con su publicación, hicimos una importante presentación del libro de Elena de la Souchère, Explication de l'Espagne. Y convinimos en que sería interesante entrar en un análisis más profundo y detallado de dicha obra. A ello venimos y nos reunimos con la autora ante el micrófono, André Camp, Jean Supervielle, y un servidor. André Camp ¿quiere usted empezar?

CAMP: Usted llama a su capítulo de presentación «Un pueblo enfermo de su historia». RAMÍREZ: ¿Qué quiere decir con ello?

SOUCHÈRE: Bueno, creo que para contestar adecuadamente tengo que contar un poco la historia del libro, la historia de mi pensamiento, de mi criterio acerca de este libro. Quería en un primer momento hacer un libro dedicado única y exclusivamente a la España contemporánea, a la España de la posguerra, a la España de los veintitrés últimos años. Pero, estudiando y planeando, estudiando los documentos y planeando el libro, yo me di cuenta que España plantea un problema que a mi juicio no plantean los otros países... en fin, la mayor parte de los otros países.

RAMÍREZ: Usted profesa la idea de que no puede hablarse de España, del hoy de España, sin conocer el ayer de España.

SOUCHÈRE: Eso. Yo creo que se puede hablar de Inglaterra prescindiendo totalmente del reinado de Victoria o del reinado de Isabel. Que se puede hablar de Alemania sin hablar de los caballeros teutónicos. Que se puede hablar de Francia, de la Francia de hoy, sin hablar necesariamente de Luis XIV. Pero creo que de España, del pasado de España no se puede prescindir, porque España tiene que resolver una serie de problemas planteados y que tienen sus raíces en la historia.

RAMÍREZ: ¿Quiere eso decir que España no vive en el presente sino en el pasado, en cierto modo? 
SOUCHÈRE: España tiene grandes dificultades en superar su pasado. Un pasado que ha sido el más glorioso de todos los países y arrastra -le sucede un poco lo que le ha sucedido a Italia, por ejemplo, durante mucho tiempo- el peso del imperio, el peso de la grandeza, el peso de un pasado fabuloso.

CAMP: El pasado pesa sobre el presente.

SOUCHÈRE: Pesa sobre el presente y ha dejado además una serie de problemas sin resolver. Por ejemplo, el problema que llamaremos de la estructura del Estado, o de la convivencia de los distintos pueblos peninsulares. Por ejemplo. Es uno de los temas.

RAMÍREZ: El problema de «España y las Españas».

SOUCHÈRE: Eso es. Uno de ellos. Otro problema -que arranca desde la Edad Media- es el problema de la tierra. El problema del latifundio, con su complemento que es el minifundio.

RAMÍREZ: Que tiene todavía características feudales.

SOUCHÈRE: Que tiene todavía, que no se ha superado del todo.

CAMP: Hay elementos también positivos, como esa civilización hecha de varias civilizaciones superpuestas, que hace del español un hombre civilizado a pesar a veces de su ignorancia. Es decir, está civilizado desde dentro y desde hace mucho tiempo.

SOUCHÈRE: Elementos positivos, naturalmente. El elemento positivo -en fin- es toda la historia de España, toda la grandeza de España, toda la civilización española. Pero un pueblo que ha tenido su época de grandeza, su problema de apogeo en el pasado, ahora tiene que seguir viviendo.

SUPERVIELLE: Claro. Y que mira un poco hacia el pasado, todavía.

SOUCHÈRE: Pues yo creo que determinadas capas sociales, tal vez las que tienen más influencia en la España de hoy. Y de ahí el título, «El tiempo inmóvil», el título de la última parte.

RAMÍREZ: De la última parte, la tercera.

SOUCHÈRE: Son capas sociales que miran más bien hacia el pasado. Pero tenemos al mismo tiempo una juventud que mira decididamente hacia el porvenir y que pugna por imponer una España nueva.

RAMÍREZ: Creo de todos modos que debe insistirse en esa idea que ha expresado usted de que no todo en el pasado es negativo. Hay muchos elementos positivos en el pasado de España. Usted habla insistentemente del sistema de los fueros y del poso que eso ha dejado. Y creo que emplea usted el término «democracia total» para caracterizar ciertas situaciones en la España del pasado, precisamente.

SOUCHÈRE: Claro, yo digo que el elemento positivo es España, es España toda. Pero usted habla concretamente del problema de los fueros, que para mí tiene especial importancia porque he nacido en Cataluña y tengo antecedentes vascos. Es decir, que para mí tiene especial importancia este problema de los fueros y este problema de la convivencia de los pueblos peninsulares.

CAMP: Sí, y tiene un capítulo especial que se llama «España y las Españas», que es significativo también.

SOUCHÈRE: Bueno, pues me parece que he empleado en alguna página de este mismo capítulo... he dicho que España en realidad es el país que ha inventado la democracia, que ha inventado la libertad.

RAMÍREZ: Seis siglos antes que los demás, lo dice usted textualmente. Sí, a eso me refería yo al hablar de elementos positivos en el pasado.

SOUCHÈRE: Sí, sí. Y probablemente una democracia mucho más desarrollada, una democracia total. Democracia foral, democracia total. Mucho más desarrollada que la 
democracia que conocemos en la mayor parte de los países del Occidente. Yo creo que en realidad el problema de la libertad -en todos los países del mundo, visto desde un punto de vista abstracto- plantea siempre dos problemas distintos. El problema de la libertad individual y el problema de la libertad del hombre, concebida como elemento que integra una comunidad. Una comunidad pueblerina [rural] ¿verdad? una aldea, un pueblo. Una comunidad regional, una comunidad cultural... en fin, las llamadas unidades culturales, que es un término que se emplea y que está bastante de moda en determinados sectores de la vida política española hoy en día. Y también el problema de la libertad del hombre concebido como trabajador pero como parte integrante de un grupo social, como elemento que integra una comunidad de trabajadores, es decir, sindicato, gremio, corporación. Y esto es lo que se había logrado en la España del siglo XIII, del siglo XIV y del siglo XV, en momentos en que ni se había planteado el problema de la libertad en otros países.

RAMÍREZ: ¿Y a qué atribuye usted eso? ¿A ese carácter individualista del español? Ésa es otra de las cosas en las que da mucho que pensar su libro de usted. Esa difícil conciliación del espíritu del individualismo español del que tanto se habla, con el espíritu colectivo que usted misma señala muy acusadamente en el hombre español.

SOUCHÈRE: Es difícil de compaginar las dos cosas. En realidad se compaginan bastante mal. De ahí una serie de luchas y de conflictos de tipo personal. Pero yo creo que en el español hay a la misma vez una aspiración individualista, una aspiración hacia una libertad total, y un sentido colectivista muy desarrollado.

RAMÍREZ: ¿Que se dan simultáneamente?

SOUCHÈRE: Que se dan simultáneamente.

RAMÍREZ: Y ésa es una de las paradojas de España, del hombre español.

SOUCHÈRE: Creo que es la paradoja fundamental del hombre español y de la vida española. Que el hombre necesita su libertad y al mismo tiempo se concibe como elemento que integra un grupo social, y que necesita en realidad -siendo muy individualista - necesita afirmar su personalidad. Y para afirmarla necesita de testigos. Tiene necesidad de afirmar su personalidad a los demás.

RAMÍREZ: ¿Pero no en forma de coro, sino de testigos que son iguales a él y que necesitan a su vez afirmar su personalidad individual? Y usted cita como ejemplo de esa tendencia constante, permanente del español, el hecho que estamos viendo en estos momentos en París, de que los españoles que se lanzan a la aventura de la emigración de una manera tal vez individual, aislada, cada uno por su lado, en cuanto están en el extranjero se agrupan inmediatamente. Vayamos por la avenida Wagram en París o por la avenida de Term, la place de Term, y allí vemos una reagrupación...

SUPERVIELLE: Es un poco también lo que sucede con los latinoamericanos, que se ven en París así agrupados ¿no? y que tienen también ese sentido muy fuerte de la libertad y del individualismo.

RAMÍREZ: Tal vez sean reminiscencias de sus orígenes españoles.

SUPERVIELLE: Supongo que sí.

CAMP: Sí, hay una definición para demostrar esa... - por ejemplo usted habla de esto en su libro- esa dificultad - no digo incapacidad-, esa dificultad para el español que vive fuera de su país de mezclarse, y sobre todo de aprender el idioma del país en el cual vive, y me recuerda la definición del desterrado español que es uno que lo ha perdido todo menos su acento.

RAMÍREZ: Sí [ríe]. 
SOUCHÈRE: Bueno, yo hablo de otra anécdota en mi libro. Es una cosa que he vivido personalmente. He conocido a un chico. Tenía aproximadamente dieciséis o diecisiete años. Recién llegado de Madrid. Uno de esos niños que habían crecido sin padre, sin escuela, en el barrio de Ventas. Y hablaba muy mal, hablaba fatal. Un español espantoso. Y después de un año de vivir en Francia, un día le planteo la pregunta: «Qué, niño ¿qué estás haciendo, qué has aprendido?» y me dice «Ahora sí he aprendido a hablar español».

[Ríen]

RAMÍREZ: Menos mal, menos mal que por lo menos ha aprendido español.

CAMP: Sí, es muy característico.

SOUCHÈRE: Vivía íntegramente entre los españoles y no sabía una palabra de francés.

RAMÍREZ: Sí, no me extraña en absoluto. Hay muchos españoles de la emigración que no han logrado aprender francés. Yo no sé. Es una actitud de inhibición, o de apego a España y a lo español... no lo sé.

CAMP: $O$ tal vez una afirmación también de...

RAMÍREZ: ¿Una afirmación de su personalidad?

CAMP: De españolismo - se puede decir- en el buen sentido, como lo que decía por ejemplo Picasso, después de tanto tiempo de vivir en Francia, que cada año se siente más español. Y ya hace cuarenta años que vive fuera de España.

SOUCHÈRE: Creo que es una fuerza vital, es una fuerza españolísima. Y eso explica por qué España ha creado un mundo, que tal vez es un fenómeno que no se ha dado en ningún país del mundo. Pues España ha creado un mundo porque los españoles al llegar a los países hispanoamericanos, no se han enterado de la forma de vivir de los indios, no han estudiado los idiomas, y sin querer y con su gran deseo de convivencia -porque eso existe también en el español, su gran comprensión y su gran deseo de convivencia con los demás- se han impuesto por su fuerza vital. Y han impuesto su idioma, su civilización, sus normas, al entorno latinoamericano y es así como ha ido creando un mundo que es totalmente español, que es un espejo de España.

RAMÍREZ: Sí, esa sociabilidad del español es precisamente el segundo elemento del díptico del que hablábamos. Frente al individualismo...

SOUCHÈRE: Individualidad y sociabilidad.

RAMÍREZ. Al mismo tiempo, al mismo tiempo. Y eso es lo que hace del hombre español una entidad muy particular que, por esa y por otras circunstancias, hace sin duda que el hombre español sea -como alguien ha dicho y creo que usted también lo recoge- el hombre que hoy vive en tensión en el mundo, el hombre que está en tensión. Tal vez porque no ha logrado todavía realizarse plenamente, porque está retrasado en la historia.

SUPERVIELLE: Pero sin embargo usted se refiere también un poco a la inercia del pueblo español ¿no? y no sólo a la tensión.

SOUCHÈRE: A la inercia, a la inercia política, me refiero en la tercera parte, dedicada a los temas meramente políticos. Yo creo que es otro planteamiento totalmente distinto ¿verdad?

RAMÍREZ: Sí, es otro tema, sí. Yo creo que si hemos agotado nuestros comentarios en torno a la primera parte, lo que podríamos hacer es recordar cuáles son los títulos de los capítulos de esta primera parte, y con ello acabaríamos de dar un cuadro bastante completo de su contenido. La primera parte - repetimos- del libro de Elena de la Souchère, Explication de l'Espagne, se titula «Presencia del pasado». El capítulo primero de esa primera parte se titula «El hombre y su circunstancia», y en él pueden leerse 
«Tierra sin agua», «El sentimiento trágico de la vida» $\mathrm{y}$ «El individualismo. El individuo en el contexto social».

CAMP: Pero ya desde el principio Elena de la Souchère plantea un problema que es uno de los problemas eternos de España y que se encuentra de nuevo en otros capítulos. Es el problema de la tierra, sin agua o con agua, de los hombres sin tierra o con tierra, y creo que hay que pasar revista por esos grandes problemas, porque encontramos, en el curso de la historia de España y hasta hoy día, ese problema de la tierra en España.

RAMÍREZ: Problema que, si ustedes quieren, desarrollaremos en emisiones venideras.

[Suena la sintonía]

ADELITA DEL CAMPO: Acaban ustedes de escuchar Explicación de España, un libro de Elena de la Souchère presentado por André Camp, Jean Supervielle y Julian Antonio Ramírez.

\section{La tierra, el agua y otros problemas seculares}

11 Año: 1962. Duración: 8 min., 38 seg. Signatura FO RP/0626. Locución: Julián Antonio Ramírez, André Camp, Jean Supervielle. Fondo sonoro: Radio París. Ramírez/del Campo.

http://devuelvemelavoz.ua.es/devuelveme-voz/visor.php? idioma=es\&fichero=9732.mp3

13 [Suena sintonía]

ADELITA DEL CAMPO: Explicación de España, un libro de Elena de la Souchère presentado por André Camp, Jean Supervielle y Julian Antonio Ramírez.

RAMÍREZ: Al iniciar días pasados, señores Camps y Supervielle, la presentación detallada del último libro de Elena de la Souchère, Explication de l'Espagne, topamos como Don Quijote y Sancho con la Iglesia- con un problema que nos propusimos desarrollar más detalladamente. El de la tierra. Apasionante tema éste de la tierra y del agua en España.

SOUCHÈRE: Pues yo lo he estudiado especialmente - he de confesar- porque soy alumna de la facultad de derecho, he iniciado mis estudios en la facultad de Barcelona, continuándolos en Francia, y luego quería hacer la escuela de ciencias políticas dedicando mi tesis de doctorado - que no he logrado doctorarme, pero dedicando mi tesis de doctorado- al problema de la tierra. Y en aquel entonces reuní los apuntes y eso he podido utilizarlo para el libro.

RAMÍREZ: ¿Los apuntes sobre este problema de la tierra?

SOUCHÈRE: Todo el problema de la tierra.

RAMÍREZ: De la tierra y del agua. Apuntes de carácter técnico.

SOUCHÈRE: Son técnicos.

RAMÍREZ: Sí, porque es un problema eminentemente técnico. En fin, es un problema también psicológico nacional. Creo que el problema de la despoblación forestal de España es un problema de psicología nacional. Del «arboricidio» español del que hablaba Antonio Machado. Es un problema latente que todavía está vivo. Y es sin duda uno de los causantes de la situación actual en ese aspecto. Pero hay algunas cosas que yo por lo menos - claro, he leído el libro de una manera un poco rápida- no he visto con excesiva claridad en su libro. Dice usted que España no es un país pobre. Claro, tomado en su conjunto, teniendo en cuenta que hay regiones muy ricas pero, en el conjunto sí es pobre, o por lo menos se ha hecho pobre precisamente a causa de ese 
problema de la falta de agua y de la falta de tierra arable, de los daños causados por la erosión.

CAMP: Y por el ganado y la Mesta.

SOUCHÈRE: Claro, es la tesis del libro, que España no es fundamentalmente un país pobre, sino un país que se ha hecho pobre, que se ha empobrecido, por la escasez de agua, y también por la despoblación forestal, por los daños ocasionados por el ganado el ganado de la Mesta-, en fin, por una serie de problemas que son a la vez problemas psicológicos, problemas naturales, y problemas sociales y económicos.

RAMÍREZ: Porque sin duda cabe pensar - por lo menos cabe suponer o esperar-que si la tierra hubiera sido propiedad de quien la trabajaba, hubiera sin duda -en general, y ahí vamos a abordar el problema del latifundio español- pues el campesino dueño de la tierra la hubiera cuidado más. Por lo menos cabe esperar eso.

SOUCHÈRE: Sí, cabe suponerlo y es casi cierto, pero hay que tener en cuenta que el esfuerzo del campesino es insuficiente si no cuenta con créditos, con recursos suministrados por el Estado, por la colectividad. De modo que tenemos al mismo tiempo un problema de reparto de la tierra -que al permanecer al margen de grandes propietarios, de terratenientes que no tienen en realidad gran interés en aprovechar totalmente los recursos naturales- pues la mayor parte de la tierra se queda sin explotar.

SUPERVIELLE: Y el campesino a veces no tiene los medios también para explotar la tierra.

SOUCHÈRE: Pero tenemos también un problema de insuficiencia de recursos, insuficiencia de créditos suministrados por el Estado, insuficiencia también de irrigación.

CAMP: El reparto de la tierra tiene también otro reparto que es el reparto del agua.

SOUCHÈRE: Reparto del agua y también reparto de abonos, semillas, ganado, herramientas...

RAMÍREZ: A este respecto del reparto del agua le voy a dar un disgusto, Elena de la Souchère. Usted habla del famoso Tribunal de las Aguas de Valencia y dice que sigue rigiendo la distribución de las aguas. A mí me han dicho confidencialmente en una de las últimas sesiones de este tribunal, el año pasado, que eso se hace de una manera folklórica ya.

SOUCHÈRE: ¿Ah, sí?

RAMÍREZ: Y me lo dijo el mismo ujier -si puede llamarse así- del tribunal, a la puerta de la Catedral de Valencia, me dijo «esto se hace para que lo vean los turistas extranjeros. En realidad, los problemas están ya resueltos». Pero en fin, quiero decir que todo eso son problemas actuales, pero volviendo a la perspectiva histórica del problema de la tierra y del agua en España, yo no recuerdo haber visto en su libro una fijación exacta del período o de los períodos históricos en que la tierra de España empieza a empobrecerse, empieza a «saharizarse», porque se emplea también ese término, «saharización». ¿Ha tenido usted ocasión de conocer datos a este respecto?

SOUCHÈRE: Hay datos pero no tan concretos. Por lo menos, en fin, no los tuve, no tuve conocimiento de ellos. Hay una evolución. Pero es una evolución que no se puede estudiar de un modo general, porque depende del tipo de cultivo, depende de las regiones, depende del clima, de elementos climatológicos, depende de una serie de problemas. Es decir, que no se puede decir que todas las tierras de España han evolucionado de la misma forma y en el mismo momento histórico. 
RAMÍREZ: Claro, claro. De todos modos, es un problema que ha pesado, uno de los aspectos del pasado que ha pesado sobre la historia de España y creo que es digno del interés que usted le presta en su libro.

SOUCHÈRE: $Y$ que sigue pesando.

CAMP: Y es un problema - eso quería decir-, un problema que queda en pie, y que seguramente es uno de los problemas vitales que tendrá que resolver España en el porvenir.

SUPERVIELLE: ¿Porque no se hizo reforma agraria en España en absoluto? ¿No hubo un principio de reforma agraria, no?

SOUCHÈRE: La reforma agraria es un tema que se ha planteado en España desde fines del siglo XVIII. Ha sido probablemente el tema más discutido en España desde hace ciento cincuenta años.

RAMÍREZ: Sí, ya desde los enciclopedistas, que empezaron a tratar ese problema.

SOUCHÈRE: Desde Jovellanos...

SUPERVIELLE: Pero nunca se llevó a cabo ningún proyecto ¿no?

RAMÍREZ: Sí, pero eso son cosas más recientes que precisamente trata el libro de Elena de la Souchère en las partes que dedica a la historia de la república, de la última república española y a la historia actual, sí. Creo que conviene terminar esta semblanza de la primera parte, recordando que el capítulo segundo se titula «La España y las Españas» y en este capítulo hay cuatro subcapítulos con los siguientes títulos: «La democracia foral» - de la que ya hemos hablado-; -no sé cómo se dirá en español centrifugeuse- «Fuerza centrífuga ibérica y centralismo castellano»; el tercer subcapítulo es «El árbol de Gernika» y como su nombre indica está dedicado al País Vasco; y el cuarto «La tierra del Gai Saber», dedicado a Cataluña como el subtítulo también indica.

Y podríamos, si ustedes lo entienden así, dejar para otro día el estudio del capítulo tercero.

[Suena la sintonía]

ADELITA DEL CAMPO: Acaban ustedes de escuchar Explicación de España, un libro de Elena de la Souchère presentado por André Camp, Jean Supervielle y Julian Antonio Ramírez.

\section{La Roma de los tiempos modernos}

Año: 1962. Duración: 12 min., 33 seg. Fondo sonoro: Radio París. Ramírez/del Campo. Signatura: FO RP/0507

http://devuelvemelavoz.ua.es/devuelveme-voz/visor.php? idioma $=$ es\&fichero $=9616 . \mathrm{mp} 3$

16 [Suena sintonía]

ADELITA DEL CAMPO: Explicación de España, un libro de Elena de la Souchère presentado por André Camp, Jean Supervielle y Julian Antonio Ramírez.

RAMÍREZ: Concluido días atrás nuestro examen del segundo capítulo de Explication de l'Espagne, de Elena de la Souchère, volvemos a reunirnos hoy con la autora André Camp, Jean Supervielle y Julian Antonio Ramírez. El capítulo tercero se llama «La Roma de los tiempos modernos» y tiene tres subcapítulos titulados: «De la reconquista a la revuelta de las masas»; el segundo «Panem et Circenses»; y el tercero «El tiempo de los pretorianos». Personalmente me ha interesado mucho este capítulo. No creo que sea 
solamente historia lo que usted plantea en él. En él ya se advierte que una de sus fuentes de inspiración han sido las lecciones, las enseñanzas de Ortega y Gasset.

SOUCHÈRE: Bueno, eso en realidad se advierte en todo el libro.

RAMíREZ: En todo el libro, sí.

SOUCHÈRE: He tratado los temas, casi todos los temas, desde un punto de vista, desde un planteamiento español, digamos. Desde una formación española, desde una filosofía. Desde el derecho español y la filosofía española. Presumo de absoluta fidelidad. No sé si lo he logrado, si he acertado, pero presumo de absoluta fidelidad a la enseñanza de los filósofos del siglo pasado, de la Generación del 98. Especialmente - usted lo dijoOrtega y Gasset. Pero hace un momento hemos hablado en el capítulo sobre el individualismo hay un subcapítulo que se titula algo como «El sentimiento trágico de la vida».

RAMÍREZ: «El sentimiento trágico de la vida» que evoca precisamente una de las obras conocidas de Unamuno, en efecto. Y este otro subcapítulo, «Panem et circenses», me ha parecido una cosa muy actual: El pan y circo. Hablaba usted de las corridas de todos y se veía en los actuales partidos de fútbol o vueltas ciclistas a los países que fueren... Pero de ello vuelve usted a hablar en la tercera parte porque es una cosa muy actual e importante.

SOUCHÈRE: Sí, eso iba a decir. Yo lo he desarrollado mucho más en la última parte.

CAMP: Sí, pero son los problemas eternos que se plantean en España, el de la tierra, el de la España y de las Españas, que sigue también, y el del panem et circenses, precisamente, y otros temas, como también el tema del aspecto religioso, el problema religioso.

SOUCHÈRE: Conviene hacer una aclaración. No es un libro histórico. Ya he dicho hace un momento que quise hacer un análisis de la situación actual, y que la situación actual plantea para mí una serie de problemas históricos. Una serie de problemas que tienen sus raíces en la Historia. En realidad no he hecho una historia de España en esta primera parte dedicada al pasado presente, a la presencia del pasado, no se trata de una historia, de un libro histórico, sino de un libro dedicado a los problemas.

RAMÍREZ: Hace usted una evocación de la historia para comprender mejor los problemas de hoy y los problemas de siempre en España.

SOUCHÈRE: Pero quiero decir que no hago tampoco una evocación de toda la historia de España sino de lo que puede aclarar, de lo que tiene relación con determinados problemas fundamentales de la convivencia española. Entre ellos, el problema de la tierra, el de la convivencia de los pueblos de la Península, el problema de la Iglesia, el problema del ejército...

RAMÍREZ: Y «El tiempo de los pretorianos» el problema del ejército. El problema de la Iglesia en el capítulo que usted titula «Esa guerra santa que siempre vuelve a empezar» $\mathrm{y}$, en el capítulo quinto, el problema eterno «Hombres sin tierra» con los dos subcapítulos, que se titulan «España tiene un atraso de una revolución» y «El pauperismo campesino y las grandes migraciones». Grandes migraciones hubo en el pasado y las hay en el presente en España. Y de eso vamos a hablar más adelante.

SOUCHÈRE: Sí, yo creo es uno de los fenómenos fundamentales de la vida española. Grandes migraciones las hubo en el siglo pasado. Es un fenómeno que ha nacido, que se ha iniciado aproximadamente en la segunda parte del siglo XIX.

RAMÍREZ: ¿Se refiere usted a las migraciones interiores?

SOUCHÈRE: Las migraciones internas, interiores, y también las migraciones externas. La emigración económica - digamos- que es una de las consecuencias de las migraciones 
internas. Es decir, que hay constantemente un éxodo, una migración de masas desde la España campesina, de la zona rural hacia las grandes ciudades.

RAMÍREZ: Precisamente como consecuencia del pauperismo campesino.

SOUCHÈRE: Del pauperismo, ése es el problema. Y al llegar a la ciudad por determinados elementos, al no encontrar trabajo, tienen que salir fuera. Entonces se plantea el segundo problema, el problema de la emigración como consecuencia de aquellas migraciones internas que son, a su vez, consecuencia del pauperismo.

RAMÍREZ: No se detiene usted muy especialmente en una emigración muy importante que hubo en España: la colonización de América. ¿No cree usted que ha ejercido bastante influencia también en el desarrollo histórico de España ese desangrarse que supuso en cierto modo?

SOUCHÈRE: Sí, yo creo que he insistido en ello - no tanto como hubiera deseado- pero he insistido bastante. Y sobre todo despoblación, eso es evidente. Despoblación, emigración masiva de la mano de obra. Pero una emigración que ha tenido otras consecuencias. La emigración ha sido una emigración marcadamente masculina. Las mujeres pocas veces han salido de España. Y en realidad tenemos una despoblación, una caída del nacimiento, que se explica porque para cada uno de los hombres que salía hacia América ¿verdad? se quedaba una mujer, una solterona sin hijos. Por una parte. Y por otra parte los que salían solían ser los más audaces, los más atrevidos, los más ambiciosos, los que tenían más inquietud y que hubieran podido aportar a la vida española su inquietud, su deseo de rejuvenecimiento, su rebelión, digamos.

RAMÍREZ: Y eso era sin duda un factor de empobrecimiento.

SOUCHÈRE: Empobrecimiento en todos los aspectos.

CAMP: Y también una constante de la vida española, usted hablaba de ese empuje que lanzó a los españoles al otro lado del Atlántico en el momento de la conquista y de la constitución del imperio colonial americano español. Pero usted da otra cifra impresionante. Usted dice que en los diez años que siguieron al año 1949 -es decir, de 1949 a 1959- muchos españoles salieron para América y es una cifra verdaderamente impresionante porque se trata de quinientas ochenta y cinco mil personas.

SOUCHÈRE: Claro, ha aumentado muchísimo la emigración en los últimos diez años, como consecuencia de los problemas económicos planteados en España.

CAMP: $Y$ cuándo uno piensa por ejemplo que al terminar la guerra unos quinientos mil españoles pudieron quedarse fuera de España, y siguen fuera de España... Y después, con esa emigración no de tipo político, sino de tipo económico... es un problema social y humano muy importante.

SOUCHÈRE: En realidad España está despoblándose.

RAMÍREZ: Sobrecogedor, sobrecogedor. Yo no sé dónde he leído un título muy inquietante que decía «España, el país de donde la gente se marcha». Es sobrecogedor, sí. Hablaba usted de emigración de hombres solos ¿Tiene ello alguna influencia en la aparición de aspectos matriarcales de la vida en España?

SOUCHÈRE: Pues a mi modo de ver me parece que el matriarcado es una tradición muy antigua, muy anterior al problema de las emigraciones. Ustedes saben que es una tradición que sobrevivía todavía en el País Vasco no hace tanto tiempo, en el siglo XIX. Y para determinados sociólogos y etnólogos -entre ellos Humboldt, sociólogo del siglo XVIII- la raza vasca, los habitantes de Vasconia, son los descendientes de los primeros habitantes de la Península. No sé hasta qué punto esta tesis - que ha sido muy discutida en nuestro siglo- es auténtica y verdadera, pero de todas formas es una posibilidad. 
RAMÍREZ: Es digna de tenerse en cuenta. Ésta que hace de los vascos los primeros españoles. Es curioso ¿verdad?

SOUCHÈRE: Los «españolísimos».

RAMÍREZ: Los «españolísimos», sí [ríe]

CAMP: Y este matriarcado se encuentra todavía en el papel que tiene la madre en la familia española, ese papel sobresaliente el de la madre.

RAMÍREZ: Omnipotente, autoridad omnipotente de la mujer en la familia.

CAMP: Que se encuentra también en la religión con el papel de la Virgen, que domina la religiosidad española.

RAMÍREZ: Y otra paradoja: papel que está en contradicción con lo difuminado del papel social y político de la mujer en España hasta ahora.

SOUCHÈRE: Es la dictadora interna en la casa y en la Iglesia. Porque está la dictadura de la Virgen también en la Iglesia.

RAMÍREZ: La preponderancia de la Virgen, sí.

SOUCHÈRE: La preponderancia. Es una verdadera dictadura. Ha exiliado a los dioses masculinos, al dios padre y a Jesús, en fin, se han visto así desplazados, es un culto a la Virgen en todos los aspectos.

RAMÍREZ: ¿Usted cree que es otro de los aspectos del matriarcado en España?

SOUCHÈRE: Del matriarcado, sí, sí.

RAMÍREZ. Es curioso. Es una teoría... pintoresca por lo menos [Ríen]. Podríamos detenernos aquí por hoy, antes de abordar el estudio detallado de la segunda parte del libro.

[Suena la sintonía]

ADELITA DEL CAMPO: Acaban ustedes de escuchar Explicación de España, un libro de Elena de la Souchère presentado por André Camp, Jean Supervielle y Julian Antonio Ramírez.

\section{Fracaso de la democracia representativa. El tiempo de las ocasiones perdidas}

Año: 1962. Duración: 12 min., 47 seg. Fondo sonoro: Radio París. Ramírez/del Campo. Signatura: FO RP/0252.

http://devuelvemelavoz.ua.es/devuelveme-voz/visor.php?

idioma $=$ es\&fichero $=9316 . \mathrm{mp} 3$

19 [Suena sintonía]

ADELITA DEL CAMPO: Explicación de España, un libro de Elena de la Souchère presentado por André Camp, Jean Supervielle y Julian Antonio Ramírez.

RAMÍREZ: Vamos a abordar en detalle la segunda parte del libro de Elena de la Souchère, Explication de l'Espagne. Para ello volvemos a reunirnos aquí junto con la autora André Camp, Jean Supervielle, y un servidor. Esta segunda parte se llama «El fracaso de la democracia representativa». Creo que usted opone la democracia representativa a la democracia que existía anteriormente en España, y que llama usted creo «democracia total». ¿Quiere usted explicarnos algo de ello?

SOUCHÈRE: Sí, el término de democracia total se refiere a la democracia foral. A los fueros, a las instituciones que existían en España desde el pasado más remoto. Y que se han concretizado en el siglo XIII - desde el siglo XIII hasta el siglo XV-y que luego 
entraron en un período de decadencia a partir del siglo XVII -fines del siglo XVI y mediados del siglo XVII-.

RAMÍREZ: Democracia que tuvo hitos muy marcados como la famosa revuelta de los comuneros, en fin... toda aquella cuestión de los comuneros y todo esto.

SOUCHÈRE: Sí, la rebelión de los comuneros -a mi modo de ver- ha nacido del encontronazo entre la tradición española -marcadamente democrática-y la voluntad de un príncipe educado en Alemania que traía, que quería traer a España las costumbres y el modo de ser, el modo de vivir de los demás países del Occidente europeo. Es decir, el derecho feudal, que predominaba en aquel entonces en los demás países y especialmente en Alemania. Es decir, que ha sido una afirmación de esta personalidad democrática de España, esta personalidad de un pueblo que ha inventado la democracia, ha inventado la libertad. En realidad, España es la madre -más que Inglaterra y más que Suiza posiblemente, o tanto como Suiza- de la democracia, es la madre de las asambleas, de los parlamentos.

RAMÍREZ: Sí, de la democracia...

SUPERVIELLE: $Y$ de los particularismos.

RAMÍREZ: Y del mismo modo que ese intento fracasó, profesa usted la idea de que fracasó la democracia representativa que es también una aportación del extranjero. Un intento de introducir en España formas de gobierno que proceden del extranjero, que están sin duda bien hechas para otros países pero que no cuadran con los factores españoles. La democracia representativa que usted presenta es ésa que intentó cuajarse en España con la monarquía de tipo constitucional, creo.

SOUCHÈRE: Sí, en realidad habían desaparecido -como decía hace un momentohabían desaparecido desde el siglo XVIII los fueros, las instituciones españolas, las instituciones tradicionales. Existía en España en aquel entonces - a partir de mediados del siglo XVII- un vacío político, digamos. Y este vacío, los liberales - primero los filósofos enciclopedistas de la generación de Jovellanos de fines del siglo XVIII-.

RAMÍREZ: Sí, los que empezaron a organizar las «sociedades de amigos», etcétera.

SOUCHÈRE: Y luego los liberales, los partidos liberales, los pensadores liberales del siglo XIX, intentaron llenarlo con las aportaciones inglesas y francesas. Es decir, hubo una especie de implantación, una especie de imposición de una tradición extranjera -de una tradición francesa e inglesa- en la vida española, con una resistencia del medio ambiente.

RAMÍREZ: Todo ello lo agrupa usted en ese primer capítulo de esta segunda parte, que titula usted «El tiempo de las ocasiones perdidas» ¿Cuáles fueron esas ocasiones perdidas?

SOUCHÈRE: La ocasión, la gran ocasión en realidad se trata del tiempo de la monarquía constitucional. El tiempo de gran libertad en que los partidos dirigentes - los partidos liberales y también el partido conservador, naturalmente- han tenido una gran libertad en realidad para orientar la vida política de España hacia una nueva estructura, hacia un rejuvenecimiento. Gran libertad por dos motivos. En realidad ha existido en España, en la constitución, en las leyes, una libertad formal. Libertad de expresión, libertad de expresarse en la tribuna del parlamento, en las cortes, etcétera.

RAMÍREZ: ¿En la monarquía constitucional?

SOUCHÈRE: En la monarquía constitucional. Es decir, que los dirigentes políticos de todas las tendencias han tenido la libertad de expresarse, la libertad de difundir sus ideas, de plantear los problemas. Y también otra libertad: no han encontrado en realidad ninguna limitación y ningún apoyo tampoco en la masa popular, en la masa 
popular más arraigada a las tradiciones. En realidad el momento de la monarquía constitucional fue un momento de indiferencia política de las masas. Es decir, que las minorías gobernantes, las minorías intelectuales, han tenido en aquel entonces la posibilidad de estructurar una nueva España.

CAMP: También es una constante -yo creo- de la vida política española que cuando hay un movimiento de masas no es hacia una tendencia liberal democrática -hablo del pasado, claro- es un movimiento de masas hacia una reacción. En contra, por ejemplo, de la intervención francesa a principios del siglo XIX y también al principio de la guerra civil.

SOUCHÈRE: Bueno, es difícil saber hasta qué punto la intervención de las masas, cuando se produce...

CAMP: Yo me refiero a las masas campesinas del Norte.

SOUCHÈRE: De cara al pasado, de cara al porvenir, en realidad las masas campesinas del Norte -como usted dice muy bien - han sido influidas por el pasado, por las instituciones tradicionales de España.

CAMP: Porque las demás se movieron poco.

SOUCHÈRE: Por un concepto democrático que predominaba en la Edad Media.

RAMÍREZ: ¿Tradicional? ¿Idealizado? El nombre de esas fuerzas políticas era «tradicionalistas».

SOUCHÈRE: Tradicionalistas. Pero un tradicionalismo que había perdido su fuerza. Un tradicionalismo un poco desvirtuado. $Y$ por otra parte se han producido también intervenciones de las masas en un sentido muy moderno y de cara al porvenir. Me refiero por ejemplo a las intervenciones a partir de 1931, que es cuando las masas han intervenido de verdad en la vida política.

RAMÍREZ: Hacia adelante, sin duda.

SOUCHÈRE: Hacia adelante, indiscutiblemente.

RAMÍREZ. Creo que hay otro factor del que habla también usted en su libro, y es el retraso en la industrialización de España. Es un factor material. Si queremos ir a una interpretación materialista de los hechos históricos, creo que hay que detenerse en ello. En España, el primer ferrocarril creo que tiene veinte o más años de retraso con respecto al primer ferrocarril francés y el inglés. 0 más, no recuerdo bien las fechas. Barcelona-Mataró.

SOUCHÈRE: Barcelona-Mataró. Sí. Aproximadamente veinte años.

RAMÍREZ: Y ese retraso en la industrialización, debido a su vez si duda a circunstancias históricas de las que ya hemos hablado, como la guerra de la independencia y otras, ha hecho también que se hayan perdido ciertas ocasiones de llevar a España hacia adelante en el plano político, en el aspecto político.

SOUCHÈRE: Claro, es un hecho fundamental. Pero este retraso - un retraso de veinte o veinticinco años- no es tampoco para dar el grito en el cielo, porque nos enseña la historia que, por ejemplo en Francia y en Alemania, se ha notado un retraso de este tipo ¿verdad? con relación a Inglaterra.

RAMÍREZ. ¿En la industrialización?

SOUCHÈRE: En la industrialización, en los ferrocarriles, por ejemplo. El desarrollo de la industria en Inglaterra se inició a fines del siglo XVIII y se inició en Francia y en Alemania en el siglo XIX. Es decir, se advierte un retraso de este tipo. Lo cual no impide que hoy en día Alemania y Francia estén más o menos al nivel, a la altura de Inglaterra en el aspecto del desarrollo de la industria. 
SUPERVIELLE: Sí bueno, pero París fue mucho más desarrollado. Virtualmente por lo menos, tenían muchas más posibilidades probablemente que España ¿no?

RAMÍREZ: Yo no sé, no habría razones muy poderosas. Tal vez la falta de hulla, la falta de carbón, la falta de energía.

CAMP: Porque las riquezas mineras de España son...

RAMÍREZ: Sí, las materias primas mineras son tan ricas como las de otros países o más. SOUCHÈRE: O más, sí.

RAMÍREZ: Y esto lo recuerda usted bien. Pero había esa falta energética, que sigue pesando.

SOUCHÈRE: La escasez de carbón, sí. Ha sido determinante.

RAMÍREZ: Que sigue pesando y que sin duda podrá resolverse de otra manera, pero que sigue pesando en la evolución, en el desarrollo español.

SOUCHÈRE: Se intentó resolver el problema mediante el desarrollo de la energía eléctrica, con grandes resultados. Hemos de reconocer que todos los esfuerzos desde hace poco más de veinte años se han dirigido al desarrollo de la energía, de las fuentes energéticas. Pero me parece que en el futuro España tendrá que resolver el problema con otras aportaciones, con la energía atómica...

RAMÍREZ: Atómica. Sin duda, sí.

SOUCHÈRE: Puede ser probablemente la única solución.

RAMÍREZ: La solución de muchos problemas españoles.

SOUCHÈRE: Porque se van agotando también las energías hidráulicas.

RAMÍREZ: Naturalmente. Pero todo esto nos lleva hacia perspectivas que desbordan un poco los límites de nuestra charla. Sería tal vez conveniente hacer un alto para reemprender la semana próxima la glosa de su interesante Explication de l'Espagne, Elena de la Souchère.

[Suena la sintonía]

ADELITA DEL CAMPO: Acaban ustedes de escuchar Explicación de España, un libro de Elena de la Souchère presentado por André Camp, Jean Supervielle y Julian Antonio Ramírez.

\section{1931, la República de los profesores}

Año: 1962. Duración: 14 min., 46 seg. Fondo sonoro: Radio París. Ramírez/del Campo. Signatura: FO RP/0253

\section{http://devuelvemelavoz.ua.es/devuelveme-voz/visor.php?} idioma=es\&fichero=9317.mp3

\section{[Suena sintonía]}

ADELITA DEL CAMPO: Explicación de España, un libro de Elena de la Souchère presentado por André Camp, Jean Supervielle y Julian Antonio Ramírez.

RAMÍREZ: Nos reunimos nuevamente con Elena de la Souchère -escritora ensayistaAndré Camp, Jean Supervielle y Julian Antonio Ramírez, a seguir comentando el libro obra suya recientemente publicado por la editorial Grasset, bajo el título Explication de l'Espagne. La semana pasada, al conjuro del lema de uno de los capítulos, titulado «El tiempo de las ocasiones perdidas», nos adentramos en cuestiones bastante complejas de la interconexión de problemas económicos y políticos a lo largo del siglo pasado en la historia de España. Pero no habíamos agotado la glosa de sus comentarios acerca de la democracia. 
Otra de las fases del fracaso de la democracia representativa creo que fue éste que llama usted en su capítulo séptimo -el segundo de esta segunda parte- «La república de los profesores». Se refiere usted a la república de 1931, claro. La otra fue excesivamente fugaz y no hay mucho que hablar de ella.

SOUCHÈRE: Bueno, yo creo que conviene hablar de este capítulo. Decir sobre este capítulo dedicado a la república -la segunda república- lo que yo decía hace un momento sobre la primera parte de mi libro ¿verdad? y de otras fases, otros momentos históricos. En realidad no se trata de un estudio y menos aún de un análisis exhaustivo de la república, de los cinco años de la república. Me limito a estudiar los problemas fundamentales de España en aquellos años de la república. Es decir, responde este capítulo a la pregunta «por qué no ha logrado, no ha conseguido la república resolver los problemas fundamentales de España», problemas planteados por la historia, que encuentran sus raíces en la historia. Por qué no se ha resuelto por ejemplo el problema de la tierra; por qué no se ha resuelto el problema de la convivencia del Estado y la Iglesia; por qué no se ha resuelto el problema del ejército, de la convivencia-digamos - entre el poder civil y el poder militar.

RAMÍREZ: Y entre el poder central...

SOUCHÈRE: $Y$ entre el poder central...

RAMÍREZ: Y los otros poderes que surgieron. Porque quiero recordar que el título del primer subcapítulo es «La república federable a pesar de ella». ¿Qué quiere usted recordar con esto? ¿Que cuando se proclamó la república de 1931 tuvo que elaborar la Constitución -en ese aspecto- a base de hechos un poco consumados, no? Como el de la autonomía de Cataluña.

SOUCHÈRE: Ustedes saben que el 14 de abril de 1931 al proclamarse en Madrid la segunda república, se ha encontrado de repente ante una hermana -una hermana primogénita- que se había proclamado, que había nacido en Barcelona pocas horas antes, que era la República Independiente de Cataluña. Porque la república fue proclamada primero en Barcelona pero la república que se proclamó en Barcelona no fue la república de España sino la república de Cataluña. De modo que se encontraba ante un hecho consumado.

RAMÍREZ: Y aún hay otra cosa -en fin, esto tal vez sea una anécdota accesoria- pero quiero recordar que la primera ciudad donde se proclamó la república fue Eibar, en la provincia de Gipuzkoa. Que por eso recibió el título de «Muy ejemplar». Se proclamó el 13 de abril de 1931. Y esta es una manifestación más de esos particularismos de los que hablábamos, de ese cantonalismo.

CAMP: De todas maneras, si la república no resolvió los grandes problemas permanentes de España, resolvió en parte -y tal vez a pesar de ella- el problema de las Españas, en cierto modo.

RAMÍREZ: Creo que no puede decirse «resolvió» ¿no?

SOUCHÈRE: No, no se resolvió. No se resolvió. En realidad yo creo que se ha malogrado la oportunidad brindada por la misma Cataluña. Porque en realidad lo que me esfuerzo por demostrar es que los catalanes - por lo menos los promotores de la independencia de Cataluña- han proclamado la independencia para poder pactar con plena libertad con los demás pueblos peninsulares. Tenemos el llamamiento de Macià y Companys a los demás pueblos peninsulares. Es decir que en realidad Cataluña quería reconquistar su libertad para poder pactar con los demás.

RAMÍREZ: Sí, con miras a una federación...

SOUCHÈRE: A una federación, claro. 
RAMÍREZ: De pueblos hispánicos o ibéricos o como quiera llamárseles, si se piensa incluso en Portugal.

SOUCHÈRE: Pensaban -eso lo sabemos históricamente porque abundan los documentos - sabemos que Companys y los dirigentes catalanes pensaban en una federación ibérica abarcando Portugal.

RAMÍREZ: Habría que contar con los portugueses, claro.

SUPERVIELLE: Ahora ¿usted cree que el particularismo catalán es esencialmente un particularismo cultural o también industrial en cierta forma?

CAMP: ¿Económico?

SUPERVIELLE: Es decir, que es un territorio económico.

RAMÍREZ. Es un complejo nacional. Creo que Cataluña es una nacionalidad con todas las condiciones características de una nacionalidad. Unidad lingüística, el primer monumento literario catalán es -creo- incluso anterior al primer monumento literario castellano...

SUPERVIELLE: Y la provincia más dinámica de España, probablemente.

RAMÍREZ: En lo industrial tiene una personalidad bien determinada.

SUPERVIELLE: Y tiene una capital, sí.

SOUCHÈRE: Es evidente que los problemas económicos planteados, los problemas de convivencia planteados por el desarrollo de la industria en Cataluña, han contribuido a crear discrepancias, a crear dificultades y a fortalecer el sentimiento nacionalista en el siglo XIX y a primeros del siglo XX.

RAMÍREZ: Sin olvidar que por producirse en España con todos esos otros problemas: el pauperismo campesino en las zonas del Sur y las migraciones que eso determina $-\mathrm{y}$ al decir esto me refiero tanto a Cataluña como al País Vasco- resulta que se ha formado una población que no está constituida únicamente por autóctonos, catalanes o vascos, sino que por ejemplo en Cataluña está constituida por los llamados murcianos y en el País Vasco por los llamados hoy "coreanos», que han contribuido a suministrar una masa bastante importante de la población y concretamente de la mano de obra de esa industria en desarrollo. Es un problema también que hay que tener en cuenta, y que sin duda hace tender al nacionalismo catalán -y creo que también al nacionalismo vascohacia una idea federativa, hispánica o ibérica.

SOUCHÈRE: Sí, eso es indiscutible. Pero hemos visto que los llamados murcianos en Cataluña, en realidad no han influido mucho en la vida catalana. Al revés, ellos han sido influidos por Cataluña.

RAMÍREZ: ¿Han sido adsorbidos por Cataluña?

SOUCHÈRE: Han sido adsorbidos. No totalmente, pero sí parcialmente.

RAMÍREZ: Se han hecho catalanes hasta lingüísticamente, con acento, porque se habla en Barcelona -en la Torrassa y en algunos barrios- se habla el catalán con acento murciano y es muy curioso.

SOUCHÈRE: $Y$ se nota una especie de patriotismo. No es un catalanismo, es una especie de patriotismo barcelonés. Son amantes, se sienten ciudadanos de Barcelona: No se sienten ciudadanos de Cataluña, se sienten ciudadanos de Barcelona.

RAMÍREZ: Todo esto son aspectos del presente. Otros de los problemas con los que tuvo que habérselas la república con mayor o menor éxito -nos lo recuerda usted en su libro - fue el problema de la tierra. Y titula usted ese subcapítulo «Reforma agraria al ralentí». ¿Qué quiere decir con ello?

SOUCHÈRE: Bueno, ustedes saben cómo se ha planteado el problema. Que después de muchas vacilaciones, después de perder casi quince meses en estudios de comisiones, 
discrepancias entre partidos políticos, la Ley Agraria se ha votado a los quince o dieciocho meses de proclamada la república, es decir, mucho tiempo perdido. Y la idea central era la creación de una especie de inventario de las tierras expropiables, de las tierras para incautar, para repartir entre los campesinos.

RAMÍREZ: Era un inventario bastante limitativo creo ¿no?

SOUCHÈRE: No, abarcaba en realidad inmensas extensiones, porque según la naturaleza de las tierras, se había previsto la expropiación de lo que sobraba a partir de... creo que diez hectáreas en regadío, trescientas en secano y, no recuerdo exactamente... según la naturaleza ¿verdad?

RAMÍREZ: Sí. Pero quiero decir, según los propietarios ¿no había una discriminación también entre propietarios? ¿No se respetaban ciertas propiedades?

SOUCHÈRE: Sí, primero se expropiaron las tierras del rey. Las tierras de determinadas colectividades. Y después de la rebelión de 1932, del intento frustrado de Sanjurjo, fueron expropiadas las tierras de la Grandeza, expropiadas sin indemnización. Por lo menos se había previsto, porque no se consiguió realizar.

SUPERVIELLE: ¿Y los bienes eclesiásticos también?

SOUCHÈRE: Bienes eclesiásticos sí, a partir de ciertas condiciones.

RAMÍREZ: Sí, en la medida en que se podía, porque se produjo por ejemplo la expulsión de los Jesuitas -que ése es otro de los aspectos interesantes- pero sin embargo no se pudo tocar mucho sus bienes, porque en realidad no...

CAMP: Y no era la primera vez.

SOUCHÈRE: No, no era la primera vez. Hay que tener en cuenta cuando se habla de las tierras de la Iglesia, las grandes propiedades eclesiásticas, que hubo ya una reforma realizada a expensas de la Iglesia en el siglo XIX, la desamortización, que fue la única reforma auténtica que se ha realizado en España. De modo que la Iglesia no figuraba en realidad entre los grandes propietarios, entre los terratenientes. $\mathrm{Y}$ hablando de las propiedades de la Compañía de Jesús, hemos de reconocer que la mayor parte de ellas aparecían como propiedades de personas privadas, o en fin, de determinados grupos.

RAMÍREZ: Todo ello, este retraso y las condiciones en que se hizo, determinaron que tampoco pudiese llevarse a cabo de una manera eficaz la solución que se había previsto para ese problema permanente de España, que es el de la tierra.

SOUCHÈRE: Sí, hemos de tener en cuenta también el poco tiempo que duró la república. Y la historia un tanto accidentada de la República.

RAMÍREZ: Y la diferencia de características. Hubo dos años de república republicana, otros dos años de república menos republicana y luego en seguida vino la guerra.

SOUCHÈRE: Sí, en realidad hubo dos años de reformas, dos años de política reformista. Porque luego vino un momento de predominancia del partico conservador, con otros nombres...

RAMÍREZ: Con otros fines políticos y otros objetivos.

SUPERVIELLE: Entonces ¿qué medidas concretas se adoptaron después de esos estudios sobre reforma agraria? ¿Se tomaron medidas prácticas o no?

SOUCHÈRE: El inventario. Y la aplicación de la reforma correspondía a un Instituto de la Reforma Agraria, le correspondía realizar la expropiación. Expropiar las tierras que figuraban, que por determinados motivos figuraban en el inventario. Bienes del rey, bienes de...

RAMÍREZ: En la fase de estudio se tomaron... yo creo recordar una ley de yunteros que constituía cierta ayuda a los campesinos pobres y medios de Extremadura y todo eso... 
Pero eran aspectos muy parciales todavía de la solución que debía aportarse al problema.

SOUCHÈRE: Hubo una serie de leyes de ayuda precisamente a los campesinos ¿verdad? Créditos, alquileres... en fin, una provisión de leyes de este tipo. Ayuda material, reparto de ganado, obras de regadío... En fin, una serie de cosas.

RAMÍREZ: Pero los problemas quedaron en pie.

Y si ustedes lo quieren, nos detendremos aquí antes de sentar, la semana próxima, la conclusión de nuestra charla en torno al libro Explication de l'Espagne.

[Suena la sintonía]

ADELITA DEL CAMPO: Acaban ustedes de escuchar Explicación de España, un libro de Elena de la Souchère presentado por André Camp, Jean Supervielle y Julian Antonio Ramírez.

\section{El engranaje desencadenado de la violencia ${ }^{11}$}

Año: 1962. Duración: 3 min., 25 seg. Fondo sonoro: Radio París. Ramírez/del Campo. Signatura: FO RP/0580

http://devuelvemelavoz.ua.es/devuelveme-voz/visor.php? idioma $=$ es\&fichero $=9708 . \mathrm{mp} 3$

RAMÍREZ: Y eso determinó la explosión, lo que usted llama «el desencadenamiento del engranaje de la violencia». La revolución, la muerte del Estado, sublevación política y guerra santa, etcétera, etcétera.

SOUCHÈRE: Un capítulo dedicado a la guerra civil pero que no es tampoco una historia de la guerra civil.

RAMÍREZ: No ha querido usted hacer una historia de la guerra civil.

SOUCHÈRE: En absoluto. Entre otros motivos porque no cabía en este ensayo de tipo político y porque existen varios libros históricos recién publicados, dedicados al problema de la guerra civil.

RAMÍREZ: De todos modos tenía usted que mencionarla, que hablar de ella, que evocarla precisamente para ver cómo en ese período también muy importante de la historia de España, seguían las constantes que estamos examinando aquí.

SOUCHÈRE: ¿Por qué seguían las constantes? Por una parte, porque no se han resuelto los problemas. Y además se ha de estudiar la forma en que el pueblo, de un modo espontáneo, en el período de la llamada «muerte del Estado», cuando ya habían desaparecido las autoridades, ha procurado resolver determinados problemas permanentes, entre ellos el problema de la tierra. Porque hubo una reforma. Hace un momento, nuestro amigo Supervielle planteaba el problema de saber si en algún momento de la historia se había llevado a cabo una auténtica reforma agraria. Sí, indiscutiblemente. Pero no fue una reforma realizada por el Estado sino una reforma realizada por el pueblo, de un modo espontáneo.

RAMÍREZ: De una manera revolucionaria, se refiere usted a la que se hizo...

SOUCHERE: En el 36.

RAMÍREZ: Sí, en la zona republicana durante la guerra.

SOUCHÈRE: Resulta que aquí, aquel problema que arranca desde la Edad Media y que tanto se ha discutido desde la época de Jovellanos hasta hoy mismo - porque estamos presenciando varios intentos y discusiones en las llamadas Cortes.

RAMÍREZ: Sobre todo en estos últimos tiempos vuelve a hablarse de ello, sí. 
SOUCHÈRE: De modo que resulta que este problema -que ha sido discutido apasionadamente desde hace casi dos siglos, siglo y medio o poco más- pues se había resuelto de un modo fulminante en unos días y de un modo espontáneo en el 36, en la zona republicana.

RAMÍREZ: En efecto.

SOUCHÈRE: Y sin ninguna intervención de las autoridades, ni nacionales ni regionales. Por ejemplo yo me refiero a la Generalitat de Catalunya. Y sin la intervención del Estado, que en realidad se puede decir que había desaparecido.

RAMÍREZ: Que no existía.

SOUCHÈRE: En fin, existía formalmente, tenía una especie de existencia -digamosmetafísica ¿verdad? Se sabía que existía un Presidente de la República, que existía un Presidente del Consejo de Ministros, que hasta celebraban sesiones, reuniones $¿$ verdad? Consejos de Ministros... pero, en fin, tenía una existencia...

SUPERVIELLE: Sin autoridad.

SOUCHÈRE: No tenía ninguna autoridad.

[La grabación finaliza abruptamente]

\section{El tiempo inmóvil. Reflexiones sobre el presente y el futuro}

Año: 1962. Duración: 12 min., 35 seg. Fondo sonoro: Radio París. Ramírez/del Campo. Signatura: FO RP/0275.

http://devuelvemelavoz.ua.es/devuelveme-voz/visor.php? idioma $=$ es\&fichero $=9358 . \mathrm{mp} 3$

[Suena sintonía]

ADELITA DEL CAMPO: Explicación de España, un libro de Elena de la Souchère presentado por André Camp, Jean Supervielle y Julian Antonio Ramírez.

RAMÍREZ: Por sexta y de momento última vez, volvemos a reunirnos con Elena de la Souchère -escritora ensayista- André Camp, Jean Supervielle y Julian Antonio Ramírez para rematar nuestros comentarios acerca del libro que acaba de publicar la editorial Grasset bajo el título Explication de l'Espagne. ¿Decía usted, André Camp?

CAMP: Yo creo que ahora es tiempo de llegar al presente y sobre todo al porvenir, porque el título mismo del libro de Elena de la Souchère, Explicación de España, se entiende si se explica lo que va a pasar.

RAMÍREZ. Sí, lo dice precisamente el editor en la contraportada, donde dice «Por razones evidentes, nada de lo que ocurre y de lo que Elena de la Souchère prevé que ocurrirá en España es extraño para nosotros, nos es ajeno». Lo dice como francés el editor. Usted llama a esta tercera parte de su libro «El tiempo inmóvil». No nos vamos a detener en ella - esta charla ha sido ya demasiado larga- pero tal vez sería interesante, si ustedes lo juzgan así también, que Elena de la Souchère nos diga con qué perspectivas ha terminado esta Explicación de España.

CAMP: Porque el elemento importante no sé si surgió después de la redacción del libro y que se incluyó y actualizó el libro, o si influyó efectivamente la entrada posible de España en el Mercado Común Europeo, es decir, es la europeización de España, que ya se veía venir desde hace tiempo, antes de que se hablara de su ingreso formal en el Mercado Común. 
SOUCHÈRE: Sí, digamos que eso es el desenlace. Bueno, contestando la pregunta, cómo he enfocado esta tercera parte dedicada al presente de España, yo les diré que -a mi juicio- existe en este libro, existe en esta tercera parte una contradicción que es reflejo de la contradicción que existe en la realidad. He titulado esta parte «El tiempo inmóvil».

RAMÍREZ: ¿A qué obedece ese título?

SOUCHÈRE: Me parece que lo que predomina en este momento $-\mathrm{y}$ desde hace veintitrés años- es un gran esfuerzo por parte de determinados elementos por detener el tiempo. Por -tal vez- volver atrás, rehacer el pasado. Reestructurar España de cara al pasado. Y al mismo tiempo -empujado por la evolución normal, por la influencia del extranjero, por la evolución de las técnicas- se nota una evolución. De modo que tenemos al mismo tiempo un gran esfuerzo por detener el tiempo y la realidad de una evolución, que se produce a pesar de este esfuerzo.

RAMÍREZ: Sí, porque a pesar de la impermeabilidad de España, las influencias del extranjero, no cabe duda que, cada vez más, la evolución del mundo ha de influir en la evolución de España.

SOUCHÈRE: Ha de influir e influye. Pero al mismo tiempo tenemos el fenómeno permanente, el fenómeno general que se produce en todas partes de la evolución de las técnicas. Y la evolución de las técnicas influye a su vez sobre la psicología del hombre, sobre el modo de vivir, sobre las instituciones, etcétera. Y además tenemos una evolución psicológica, que se debe a la aparición de una nueva generación, una nueva generación que ha sido educada, se ha formado en un ambiente distinto, y que - no digo en todos los casos, pero sí en determinados casos- es una evolución que se produce en forma de rebelión contra las influencias.

CAMP: Yo creo que hay varias nuevas generaciones. Porque usted habla bastante detenidamente de la generación del 51, que es diferente de la del 61 , del $62 \ldots$ Y cada diez años hay generaciones que actúan y tienen importancia más fuerte - tal vez-con el tiempo.

RAMÍREZ: Lo importante -creo- es saber, como dice usted, que esta generación o estas generaciones están libres de los factores de inmovilidad.

SOUCHÈRE: Claro. En realidad están libres de las herencias de la guerra. No han vivido la guerra, están libres, se encuentran libres de las rencillas y del miedo, que son los dos factores determinantes - $i$ verdad?- producidos por la guerra.

CAMP: Porque la generación del 51 -según su estudio, que me parece además muy justo- es una generación de jóvenes que no conocieron la guerra civil, pero que tienen una reacción en contra de lo anterior, del pasado, de los padres, de la estructura social... Pero, sin tener una idea constructiva, yo creo. Es una forma negativa de oposición sin construcción, que también forma parte del temperamento español temperamento un poco anarquista - y al contrario, la joven España - como usted llama a la generación que llega ahora- es una generación que parece más constructiva y con la cual se puede contar más ¿no?

SOUCHÈRE: Sí, posiblemente son muy jóvenes. En realidad les conocemos poco, porque los mayores no conocemos a los chicos, a los adolescentes. Pero cabe suponer que enfocan el presente y el porvenir de España tal vez de un modo más constructivo, en la medida en que se encuentran más libres aún de los temores y de las rencillas producidas por la guerra. Volviendo a este fenómeno generacional tan importante en España, hay algo extraño. Hay que pensar que estamos hablando de dos generaciones distintas, con diez años de distancia. El mismo Ortega y Gasset -que concedía tanta 
importancia al fenómeno generacional- establecía un mínimo de quince años entre dos generaciones. Pero yo creo que lo que importa en este momento, lo que conviene destacar es que estamos hablando de una minoría selecta, de una minoría intelectual de los estudiantes.

CAMP: Sí, de los estudiantes.

RAMÍREZ: ¿Y qué pasa con el pueblo y con la masa en ese momento?

SOUCHÈRE: Yo creo que en la masa, en la juventud, no se nota una evolución tan marcada, tan evidente. Por ejemplo, no veo tanta diferencia entre los jóvenes de veintiocho o treinta años y los jóvenes de veinte años. El fenómeno es más bien un fenómeno de dos generaciones estudiantiles, es decir, de dos momentos de la vida de la universidad. Porque unos han terminado su ciclo universitario, ya han salido de la universidad y se han incorporado a la vida activa -algunos se han casado-y los demás están iniciando su vida y sus estudios en la universidad. De modo que, en este sentido, se puede hablar casi de dos generaciones de estudiantes. Pero en la vida práctica, en la vida de la mayor parte de la población, en la mayor parte de la juventud, no interviene este fenómeno de la continuidad y discontinuidad de la vida universitaria. De modo que son otros fenómenos, y por lo tanto no se nota en la juventud campesina o entre la clase media o la juventud obrera una diferencia, una evolución tan marcada.

RAMÍREZ: Con respecto al estado de ánimo de hace... ¿quince años, digamos?

SOUCHÈRE: Diez o quince años.

CAMP: Pero la juventud universitaria es un reflejo adelantado -se puede decir- del despertar a una vida política de todo un país. Es más avanzada respecto a las demás juventudes, campesinas u obreras. Porque lo que se notaba en la generación por ejemplo del 51 y los diez años que siguieron a la guerra de España es una especie de atonía en lo que se refiere a la política.

RAMÍREZ: ¿En la juventud en general, quiere usted decir?

CAMP: La juventud se había alejado de la política y desconocía los problemas políticos, se había «cloroformado» un poco desde el punto de vista político. Y tal vez ahora, en estos últimos años, con una corriente más fuerte, el aislamiento español que se ha roto, la salida de jóvenes fuera de España y la llegada a España de extranjeros, se han creado corrientes y se ha creado también una conciencia política de la juventud universitaria que es la que capta primero los influjos extranjeros, extraños, y se nota - yo creo-y también demuestra la integración posible y venidera de España en Europa.

RAMÍREZ: Sí, ahí entramos ya en el capítulo de los vaticinios, y yo no quiero pedirle a usted que haga de pitonisa. Pero si tuviera que escribir una cuarta parte de su libro ¿cómo cree usted que titularía esta cuarta parte? Qué pregunta ¿verdad?

SOUCHÈRE: Pues ojalá no se titule «El tiempo de las ocasiones perdidas». Ojalá no se parezca demasiado al período del 1876, porque yo creo que el problema de España se va a plantear exactamente en los mismos términos que en el año 76 , con grandes oportunidades.

RAMÍREZ: Y con caracteres más acuciantes.

SOUCHÈRE: Y claro, con problemas urgentes.

RAMÍREZ: Con caracteres más acuciantes. Pero como dice usted en el último párrafo de su libro, el pueblo español es un pueblo muy vivo, y todo lo que ha realizado de grande ha sido casi siempre improvisado, precipitado, en la angustia y en el fervor.

CAMP: Yo creo también que no hemos agotado el tema ni la sustancia que tiene el libro de Elena de la Souchère, Explicación de España, pero espero también que estas charlas con ella darán el gusto, a los oyentes y a los que nos han escuchado durante estas 
últimas semanas, de conocer el libro de Elena de la Souchère y de leerlo, y también de comentarlo como hemos hecho estos días, y por lo cual agradecemos a Elena de la Souchère. Recuerdo también el título de su libro, Explication de l'Espagne, en la editorial Grasset de París.

[Suena la sintonía]

ADELITA DEL CAMPO: Acaban ustedes de escuchar Explicación de España, un libro de Elena de la Souchère presentado por André Camp, Jean Supervielle y Julian Antonio Ramírez.

\section{NOTAS}

1. Este artículo forma parte del proyecto «Itzuli nire ahotsa. Los programas vascos emitidos por Radio París durante la dictadura franquista», nacido de la convergencia entre la labor de la Mario Onaindia Fundazioa en pro de la memoria histórica vasca y el proyecto online «Devuélveme la voz» de la Universidad de Alicante <http:// devuelvemelavoz.ua.es/>. Ha sido financiado por el Gobierno Vasco y la Diputación Foral de Guipúzcoa.

2. Juan Goytisolo, «Celebración de Elena de la Souchère», El País, 19 de julio de 2005. Incluido asimismo como prólogo de la obra Elena Rivera de la Souchère, Lo que han visto mis ojos. Crónicas de la España republicana, Madrid, Galaxia Gutenberg, 2007, p. 9-13.

3. Véase Ramón Chao, «Radio París: una ventana a la democracia», Triunfo, Madrid, 8 de abril de 1978, p. 38-39, y los textos de Gérard Malgat, Voix de la France, voix de l'exil. Les émissions en langue espagnole de la Radiodiffusion Française entre 1945 et 1968, Mémoire de DEA, Université de Paris XNanterre, 1997, p. 19-23, «Aquí París, André Camp o una vida radiofónica» <http:// devuelvemelavoz.ua.es/es/radio-paris-andre-camp/aqui-paris-andre-camp-o-una-vida-

radiofonica.html> [6 de febrero de 2018] y «Las voces exiliadas de Radio París», Historia Actual Online, $\mathrm{n}^{\circ} 42$ (1), 2017, p. 99-112.

4. Ramón Chao, op. cit., p. 39.

5. Sobre Julián Antonio Ramírez y Adelita del Campo véase Julián Antonio Ramírez, Ici París, Memorias de una voz en libertad, Madrid, Alianza Editorial, 2003; Antonina Rodrigo: «Adelita del Campo: ¡Aquí Radio París!», en Mujer y exilio 1939, Madrid, Compañía literaria, 1999, p. 239-259; Antonio Teruel, «Adela Carreras Taurà, "Adelita del Campo". Activista política y cultural, locutora de la emisora "Radio París" durante el franquismo", Diario Información, Alicante, 20 de mayo de 2016; así como la entrada "Julián Antonio Ramírez Hernando» de la Auñamendi Eusko Entziklopedia http://www.euskomedia.org/aunamendi/102033 [20 de septiembre de 2016] y el apartado «Julián Antonio Ramírez y Adelita del Campo» del portal «Devuélveme la voz» http:// devuelvemelavoz.ua.es/es/julian-antonio-ramirez-y-adelita-del-campo.html [20 de septiembre de 2016].

6. Sobre su biografía, además de Elena Rivera de la Souchère, Lo que han visto mis ojos..., véanse sobre todo: Juan Goytisolo, «Elena Rivera de la Souchère, luchadora contra la dictadura», El País, 15 de septiembre de 2016; José Andrés Rojo, «iEsta maldita condición femenina! », El País, 25 de julio de 2007; Entrevista a «Elena de Rivera de la Souchère», por Elena Poniatowska en Jardín de Francia, México, Fondo de Cultura Económica, 2013 [versión ebook]; «Elena Rivera de Souchère» 
de la Auñamendi Eusko Entziklopedia <http://www.euskomedia.org/aunamendi/108439> [06 de febrero de 2018].

7. Elena Rivera de la Souchère, Lo que han visto mis ojos..., p. 64, 80-81, 94-102. Luis Monferrer Catalán, Odisea en Albion. Exiliados republicanos en Gran Bretaña 1936-1977, Madrid, Ediciones de la Torre, 2007, p. 419-421. Joseba M. Goñí Galarraga, «Alberto de Onaindía, sacerdote resistente: magisterio radiofónico desde el exilio», en La cultura del exilio vasco: Euskal erbestearen kultura, Donostia, Saturraran, 2000, vol. 2, p. 395-426.

8. Si bien es cierto que muchos elementos del libro fueron reutilizados por la autora en Lo que han visto mis ojos...

9. El Boletín de Orientación Bibliográfica (1963-1976) fue una publicación de circulación restringida dedicada a analizar obras publicadas fuera de España, generalmente prohibidas por la dictadura. Creado por Manuel Fraga y su equipo ministerial, estaba integrado por censores (con Ricardo de la Cierva en cabeza) y servía esencialmente de réplica ideológica y propaganda de consumo interno para los altos cargos políticos del franquismo. Sus artículos, no obstante, eran anónimos. Francisco Rojas Claros, Dirigismo cultural y disidencia editorial en España, 1962-1973, Publicaciones de la Universidad de Alicante, 2013, p. 48-50. Aránzazu Sarría Buil, «El Boletín de Orientación Bibliográfica del Ministerio de Información y Turismo y la editorial Ruedo Ibérico», en Nathalie Ludec y Françoise Dubosquet Lairys (coords.), Centros y periferias: prensa, impresos y territorios en el mundo hispánico contemporáneo: homenaje a Jacqueline Covo-Maurice, París, PILAR, 2004, p. 233-253.

10. MINISTERIO DE INFORMACIÓN Y TURISMO, «Explication de l'Espagne de Elena de la Souchère», Boletín de Orientación Bibliográfica, ํㅡㄴ 1, Madrid, enero de 1963, p. 15-25.

11. De esta grabación sólo se ha conservado un fragmento. Probablemente nunca llegó a emitirse.

\section{RESÚMENES}

Transcripción de las ocho grabaciones conservadas de «Radio París» del programa radiofónico «Explicación de España, un libro de Elena de la Souchère» (1962), mesa redonda integrada por la autora del texto y tres importantes personalidades de la emisora: los hispanistas franceses André Camp y Jean Supervielle, y el locutor donostiarra exiliado Julián Antonio Ramírez.

Transcription des huit enregistrements conservés de «Radio Paris» de l'émission radiophonique «Explication de l'Espagne, un livre d'Elena de la Souchère» (1962)table ronde composée de l'auteur du texte et de trois personnalités importantes de la chaîne: les hispanistes français André Camp et Jean Supervielle, et le présentateur de Saint-Sébastien en exil Julián Antonio Ramirez.

Transcription of the eight recordings preserved by Radio Paris of the radio program 'Explanation of Spain, a book by Elena de la Souchère' (1962)round table composed of the author of the text and three important personalities of the station: the French Hispanists André Camp and Jean Supervielle, and the exiled San Sebastian broadcaster Julián Antonio Ramírez. 
ÍNDICE

Palabras claves: Hispanismo, antifranquismo, exilio, radiodifusión, fuentes históricas Mots-clés: Hispanisme, antifranquisme, exil, radiodiffusion, sources historiques

Keywords: Hispanism, antifranquism, exile, broadcasting, historical sources

\section{AUTORES}

FRANCISCO ROJAS CLAROS

Universidad de Alicante

MARÍA LOSADA URIGÜEN

Universidad del País Vasco / Euskal Herriko Unibertsitatea

\section{GAIZKA FERNÁNDEZ SOLDEVILLA}

Fundación Centro para la Memoria de las Víctimas del Terrorismo 